\title{
CONSTRUÇÕES E CONSTRUTORES NA BAIXA IDADE MÉDIA: EM TORNO DA MAÇONARIA OPERATIVA.
}

\section{VICTOR DEODATO DA SILVA \\ Disciplina: História Medieval.}

Muitas controvérsias têm cercado as atividades, os ritos e a doutrina das sociedades maçônicas. Suas cerimônias noturnas, o aperto de mão especial e sua ação social e política têm sido objeto de muitas divergências de interpretação, o que não é dificil de se entender. Sem absolutamente negar o interesse de pesquisas quanto a esses aspectos, desejamos salientar que deles não vamos tratar neste trabalho, concentrando nossas atenções no problema das origens - ou melhor, no processo que conduziu as associações profissionais ligadas ao setor da construção da Baixa Idade Média a adquirirem a sua atual orientação filantrópica e esotérica - o qual, observe-se, não é em nada menos controvertido do que o da atuação maçônica.

Mas, o maior problema não reside no envolvimento em polêmicas, havendo outros mais graves como a dificuldade de acesso à moderna bibliografia sobre a matéria, especialmente para os não iniciados, situação que é exatamente a nossa. Naturalmente, como ocorre com relação a qualquer tema de história geral, deve-se contar com a precariedade das nossas bibliotecas, mas em relação aos estudos maçônicos a situação se complica, visto que o recurso à encomenda em livrarias ou ao pedido de cópias xerográficas por meios usualmente eficientes fica bloqueado pelo fato de as obras sobre a matéria serem geralmente publicações de entidades maçônicas e, em decorrência disso, objeto de circulação limitada. Está nesse caso o periódico Ars Quatuor Coronati, editado em Londres e cujas páginas tem abrigado trabalhos de consideravel importância científica. Igualmente infrutíferas resultaram nossas tentativas de acesso às obras básicas em co-autoria de $\mathrm{D}$. Knoop e G. P. Jones (1), o que nos obrigou a contentarmo-nos com

(1). - Especialmente The Medieval Mason, Manchester, 1933 e The Genesis of Freemasonry, Manchester, 1949. Reflexos desses trabalhos podem ser detectados em obras de outros autores como p. ex., de J. GIMPEL: Les Bâtisseurs de Cathédrales, Paris, 1958. 
trabalho de menor monta do segundo desses dois autores, os quais, sem dúvida, permitem conhecer suas conclusões e principais idéias (2).

As insuficiências das fontes têm, por outro lado, favorecido as especulações relativamente às origens da "Franco-Maçonaria", onde durante muito tempo campearam as teorias mais fantasiosas (das quais só trataremos ocasionalmente, pois um exame mais detalhado nos levaria muito longe), o que, neste século, tem provocado reações cada vez mais radicais nos próprios meios maçônicos (3). O objetivo do presente artigo (4) não é exatamente o de reforçar essa tarefa de demolição e, menos ainda, o de aventar novas teorias (o que já existe de sobra!), mas apenas o de questionar determinadas conclusões, enfatizando alguns aspectos que, parece-nos, não têm sido suficientemente tomados em conta e que, se devidamente aprofundados, o que ainda não é nosso caso, poderão presumivelmente esclarecer alguns pontos significativos, sendo que realçaremos sobretudo a influência da depressão do fim da Idade Média na configuração de uma característica típica da Maçonaria dos tempos modernos: a da predisposição para o combate, ou, pelo menos, a de aglutinar a resistência à opressão. Sem dúvida, há pouco em comum entre as razões essencialmente profissionais dos movimentos dos "maçons" medievais e a generosidade das causas que empolgaram as sociedades maçônicas em épocas mais recentes (para não ir muito longe, basta evocar a sua participação na Independência do Brasil), mas, de qualquer forma, as bases dessa tradição foram então lançadas. Como os assuntos maçônicos não são suficientemente difundidos entre nós, julgamos oportuno situar preliminarmente alguns aspectos gerais das questões que eles envolvem para maior clareza da parte específica deste trabalho.

$O$ carater fechado das entidades que teriam dado origem às atuais sociedades maçônicas explica em boa parte as dúvidas que campeiam nesse terreno, sendo util, porem, destacar que, quanto às formas atuais

(2) . - G. P. JONES é autor do artigo "Freemasonry" da ENCYCLOPAEDIA BRITANNICA, ed. 1965, T. 9, pp. 840-843 e do capítulo VIII "Building in Stone in Medieval Western Europe, do Vol. II da The Oxford Economic History of Europe, Oxford, 1952, pp. 493-518.

(3). - Alem dos trabalhos citados nas notas anteriores, enumeremos entre os mais antigos: Albert LANTOINE: Histoire de la Franc-Maçonnerie Française. La Franc-Maçonnerie chez elle, Paris, 1927 e Lionel VIBERT: La Franc-Maçonnerie avant l'existence des Grandes Loges (trad. do inglês por F. Duriez), Paris, 1950.

(4). - Nesse sentido, desejamos salientar que o presente trabalho somente se tornou possivel graças ao apôio do Dr. Teobaldo Varoli Filho, da Loja Grande Oriente de São Paulo, que, alem de preciosos esclarecimentos verbais, permitiu-nos o acesso à Bibliografia espećfica mencionada no correr do trabalho e a quem apresentamos nossos melhores agradecimentos. Devemos frisar ainda que a utilidade de seu livro Curso de Maçonaria Simbólica, T. 1, São Paulo, s/d, foi muito maior do que a indicada pela frequência das citaçōes em notas. 
da Instituição, uma data muito precisa pode ser evocada: 24 de junho de 1717, quando verificou-se a fusão das quatro lojas de Londres na "Grande Loja Inglesa" (5). Esse acontecimento marca o nascimento oficial da Maçonaria dita especulativa, ou seja, o estágio em que as preocupações especificamente profissionais - ligadas ao setor das construções - tornaram-se irrelevantes, subsistindo apenas na forma de símbolos, daí se difundindo por todo o mundo, a começar pela França, cuja "Grande Loja Inglesa de França" aderiu formalmente em 1732 à orientação da sua precursora londrina (6) . Nesse momento, a Maçonaria se delineia como uma comunidade de iniciados, obedientes a um corpo de doutrina que representa a confluência de uma série de princípios morais, herméticos e mesmo ideológicos assaz heteróclitos, provenientes que são de origens as mais variadas. Observe-se, contudo, que usamos - e o fizemos intencionalmente - a expressão "nascimento oficial", visto que tais tendências já vinham se fazendo presentes nas sociedades maçônicas e que, antes mesmo da fundação da "Grande Loja Inglesa" nós podemos dar como plenamente constituida uma outra associação, estribada numa organização ritual e doutrinária consideravelmente distinta e que, até nossos dias, tem se situado numa posição até certo ponto particularista quanto à corrente maçônica central, em linhas gerais vinculada às diretrizes inglesas, a saber, o chamado "rito escocês" (7), de inclinação filo-católica e aristocrática, em contraste com a conotação protestante e burguesa da tradição inglesa (8). Não obstante, esse, como outros particularismos (9), acabaram por se fundir na orientação inglesa, que hoje reina inconteste nos meios maçônicos, não obstante a subsistência nos mesmos de elementos oriundos de outras observâncias.

(5). - Deve ser ressaltado que esse acontecimento, mesmo na esfera inglesa, somente com o tempo implicou na unificação das práticas maçônicas, dada a rivalidade da "Velha Loja de York". L. VIBERT, op. cit., pp. 135 sqq.; Bernard E. JONES: The Freemasons Guide and Compendium, Londres, 1955, pp. 168 sqq.; Paul NAUDON, La Franc-Maçonnerie, Paris, 1974, pp. $30 \mathrm{sqq}$.

(6) . - A. LANTOINE, op. cit., pp. 54 sqq., fala da fundação da Loja "Au Louis d'Argent" em 1725, enquanto P. NAUDON, op. cit., p. 36, retroage a 1721 .

(7). - L. VIBERT, op. cit., pp. 134 sqq.; P. NAUDON, pp. 28 sqq.

(8). - A. LANTOINE, pp. 93 sqq., demonstra mui convincentemente as conexóes entre a rivalidade das sociedades maçônicas inglesa e escocesa e as querelas do período Stuart. Sendo o catolicismo a religião predominante na França e dadas as precedentes ligações do último país com o anteriormente citado, teve o rito escoces grande difusão, ao que parece antecedendo mesmo o de orientação inglesa. V. P. NAUDON, pp. 35 sqq. e sobre o rito escocês pp. 28 sqq. e 98 sqq.

(9). - Mesmo a "Grande Loja Inglesa de França", oficializada em 1732 junto à "Grande Loja Inglesa", parece ter se constituido já em 1725, explicando-se essa demora pela eventual relutância em abrir mão de sua autonomia. V. LANTOINE, pp. 54 sqq. e NAUDON, pp. 35 sqq. 
Isso nos permite, portanto, constatar que, para tratar dos antecedentes da atual "Franco Maçonaria" devemos dar uma atenção especial ao ocorrido na Inglaterra, visto que foi nesse país que se concretizou a transição definitiva da Maçonaria dita "operativa" - de carater eminentemente profissional - para aquela classificada como "especulativa" - preocupada antes de tudo com problemas esotéricos e morais - e isso não obstante o fato de a primeira das duas fases da Instituição ter apresentado manifestações análogas no Continente. A consolidação da supremacia inglesa marcou a vitória đe uma tendência centralizadora que, nos termos em que se verificou, era estranha aos meios maçônicos. Sem dúvida, na época em que neles predominavam os profissionais do setor de construção, mais do que em relação a outros ofícios, eram aí as comunicações bastante intensas, mas sem levar à constituição de uma confederação de sociedades ligadas a uma sede central, como é o caso da Maçonaria atual.

Visto, porem, que o tema do nosso trabalho não é a Maçonaria atual ou especulativa, mas sim a operativa e, mesmo ela, sobretudo nas suas primeiras manifestações documentadas e como em nenhum campo é possivel estabelecer um vínculo mais nítido entre a modalidade especulativa e a operativa que a precedeu, do que o da terminologia básica, vamos nos deter um pouco no exame dos termos maçon e franco e daquele que designa sua sede de reuniões, a loja.

Sobre a origem do termo maçon poucas são as dúvidas: ele vem do francês medieval (maçon ou masson) e designa um trabalhador de construção (10). No francês moderno maçon significa pedreiro, mas essa acepção não deve ser aceita para o período medieval, em que se referia àquele que trabalhava com pedras (11) e, por extensão, em construções de grande vulto, e mesmo aos escultores, não se aplicando aos que lidavam com cal e tijolo (12). No caso do pedreiro-mestre -

(10). - Algumas das explicações aventadas para indicar a etimologia deste termo dão bem uma média da fantasia que durante muito tempo ce cou os estudos maçônicos, chegando-se a propor que maçon viria da junção de mai, amar (?) e son, irmão (em que língua? Nas germânicas significa filho!), significando portanto amar ao irmáo. Para esse e outros étimos v. B. E. JONES, p. 145.

(11). - E tambem todo o material duro, como o mármore, alabastro, granito, etc. Inclusive o concreto, obtido pelos romanos mediante mistura de vários materiais, pode ser incluido no caso. Em relação aos estilos românico e gótico ể de praxe frisar a ausência do mármore, alabastro e outros materiais considerados luxuosos, mas tal observação não é válida para as construções italianas contemporâneas ao florescimento desses estilos, em relação às quais o uso dessas pedras era bastante comum.

(12) . - A. LANTOINE, p. 7: "Évidemment il ne faut pas donner à ce mo: l'acception trop simpliste de gâcheur de mortier, et il ne faut même jamais la donner". V. tb. Th. VAROLI Fo: op. cit., p. 9. 
visto que a profissão seguia em linhas gerais a hierarquia básica relativamente aos ofícios, com os seus três graus de aprendiz, companheiro e mestre (13) - a sua função estaria próxima do arquiteto moderno, apesar de se diferenciar deste pelo fato de sua atividade não se restringir à elaboração do projeto e à fiscalização de sua execução, comprometido que estava com os trabalhos, mesmo os braçais, necessários à sua concretização (14) .

Uma questão sensivelmente mais delicada é a que envolve o qualificativo inseparavel do maçon atual, ou seja, livre ou franco e que tem o seu equivalente nas principais línguas ocidentais (free em inglês, frei em alemão, libero em italiano, etc.). Era ele generalizado em toda a Europa Ocidental na fase operativa, tendo sido interpretado, uma vez eliminadas conjecturas fantasiosas, em pelo menos quatro sentidos diversos: num deles designaria o material objeto dos trabalhos, a franche peer ou pedra livre, apropriada aos trabalhos delicados, inclusive de escultura, por oposição à pedra dura mais comum, significado em que não teria nenhuma implicação jurídica (15), enquanto nos demais pode referir-se à condição do trabalhador. Free, franc, libero, etc. aludiriam alternativamente à situação jurídica do indivíduo (contrapondo-se aos dependentes de qualquer grau), o que seria indicativo de um trabalhador de nivel social mais elevado, à sua ausência de laços com associações profissionais juradas (guildas, corporações, etc.), regulamentadas pelos poderes públicos (em geral municipais); e, por último, à sua capacidade legal de deslocar-se livremente de um ponto a outro, sendo que em qualquer destas três últimas acepções as limitações somente deveriam ser temporárias, decorrentes de contratos livremente

(13) . - Robert Freke GOULD: The Concise History of Freemasonry, Londres, 1951, pp. 26 sqq.; L. VIBERT, pp. 81 sqq.

(14) . - Todavia, se esta era a atitude geral do período em suas expectativas com relação ao pedreiro-mestre, existem indícios de que já existiam entre estes muitos que adotavam o comportamento característico do arquiteto atual, ou seja, praticamente apenas elaboravam os projetos e dirigiam sua execução, provocando inclusive a indignação de teólogos e predicadores, como é o caso de Nicolau de Biard nos meados do século XIII, escandalizado ao constatar que "homens de uma arte mecânica não mais trabalhavam manualmente". (citado por J. GIMPEL: op . cit., p. 134; ademais, todo o cap. VII dessa obra, pp. 105-143 é muito sugestivo a esse respeito). V. tb. B. E. JONES, pp. 44 sqq. Por outro lado R. F. GOUI.D, op . cit., mostra que os construtores eram designados por termos tais como Ingeniator, Supervisor, Magister Operum e, em inglês, Keeper of the Work ou Keeper of the Fabric, o que significa um tratamento diferenciado em relação ao conjunto dos trabalhadores manuais.

(15). - Tomando o inglês como referência freemason seria uma abreviação de freestone mason, explicação que não deixa de ser problemática apesar de se fundar na existência comprovada dos termos franche peer, freestone, etc. - mas que conta com a adesão de G. P. JONES, nos trabalhos acima citados na nota (2), constituindo-se mesmo num dos elementos chaves da argumentação em apôio à sua tese de desvinculação da maçonaria operativa de quaisquer preocupações extra-profissionais mais pronunciadas. 
assumidos (16). Dadas as controvérsias em torno do assunto, apenas desejamos sublinhar que não existe incompatibilidade entre os três últimos sentidos e que o derradeiro, o da faculdade ilimitada de locomoção, é o que melhor explicaria o carater fundamentalmente internacional que caracteriza a maçonaria moderna.

Por último, quanto à loja, do germânico antigo laubja, tratava-se de um sinônimo de hut (cabana), designando a dependência de descanso dos trabalhadores de construção - em geral construida de madeira e de carater precário - situada ao lado do canteiro de obras e por eles frequentada durante os intervalos do trabalho. Tornando-se comuns as discussões sobre os problemas de serviço durante esses descansos, a loja acabou por se tornar um local de assembléia por excelência, e daí a sede de cada comunidade maçônica (17).

Verificamos, desta forma, que ao menos quanto à terminologia básica, as origens da atual Maçonaria situam-se claramente na fase dita operativa. Algumas questões, porem, ficam ainda de pé, tais como: sendo a Maçonaria uma associação, quais as características das sociedades que deram origem às atuais lojas maçônicas? Como explicar a incorporação pela Maçonaria de símbolos e doutrinas de procedência tão diversa? Qual o mecanismo que presidiu à mudança da orientação operativa ou profissional, para a especulativa ou doutrinária? Qual a origem dos seus ritos de iniciação e senhas secretas de reconhecimento?

Para essas perguntas, em consequência da insuficiência das fontes subsistentes, não há respostas seguras e, alem desses, muitos outros pontos de menor interesse no momento permanecem igualmente mal esclarecidos, mas um dado pode ser considerado bem documentado: a fase de transição situa-se - sempre no que concerne à "Companhia Maçônica de Londres" - no século XVII, conservando-se as sociedades maçônicas basicamente profissionais até o XVI e tornando-se decididamente especulativas a partir do XVIII. A partir dos meados do século XVII está seguramente comprovado o ingresso na aludida Companhia de um número crescente de membros não operativos, os quais eram qualificados como aceitos, de onde a denominação dessa fase como Maçonaria de Aceitação, sendo que em relação à Escócia isso ocorria em data ainda mais precoce, ou seja, em 1600 (18). Mas, trata-se dos casos inequivocamente comprovados, devendo-se supor que casos

(16). - VIBERT, pp. 17 sqq. Por outro lado, alem dessas etimologias plausíveis existem muitas outras de carater pronunciadamente fantasioso, examinadas em detalhe por B. E. JONES, pp. 145 sqq.

(17). - R. F. GOULD, pp. 66 sqq.; B. E. JONES, pp. 35 sqq.

(18). - VIBERT, pp. 79 sqq.; B. E. JONES, pp. 159 sqq. Por seu turno, P. NAUDOT, p. 28, sublinha que já em 1439 eram impostos às lojas escocesas como "grão-mestres hereditários" os senhores Saint-Clair de Rosslyn por Jaime II. 
não documentados tenham se verificado anteriormente (19), sendo, por exemplo, provavel a presença de elementos do clero desde os inícios das confrarias maçônicas, dadas as ligações estreitas entre estas e a Igreja, sobretudo se tiver algum fundamento a teoria dos monges construtores (20).

Em suma, não obstante alguns elementos fundamentais da Maçonaria serem indubitavelmente de origem medieval, em relação a outros persistem muitas dúvidas, devendo-se tal situação ao fato de a Instituição cultivar o sigilo relativamente a muitos aspectos de sua atuação, sigilo esse que, por sua vez, frequentemente pode remontar às associações que deram orígem à atual Sociedade (21), de onde a multiplicação de incertezas. Ás incertezas adiciona-se o fato de muitos traços característicos da atual Maçonaria (22) coincidirem, em um ou mais pormenores, com o de coletividades das mais diversas épocas e lugares, fornecendo pretextos a genealogias as mais esdrúxulas (23), o que explica, por sua vez, a proliferação das polêmicas. Para que o fato de colocarmos em dúvida a maior parte dessas explicações não seja inter-

(19). - Um dos documentps mais antigos, o chamado MS. Cooke, que data de c. 1400, e que contem a história lendária da Confraria de Londres, fala do rei anglo-saxão Edwin (século $X$ ) como membro admitido. Como bem observa VIBERT, p. 79: "On peut accepter ou dénier comme fait historique la présence d'Edwin dans notre Ordre au Xe siècle; quoi qu'il en soit, il est clair que la pratique d'admettre dans la confrérie des non operatifs que leur position ou leurs connaissances y pouvaient justifier se faisait déjà au moment de la compilation đu document Cooke, c'est-à-dire vers 1400 , sinon plus tôt".

(20) . - B. E. JONES, pp. 41 sqq. Esses monges, embora participassem do projeto e da supervisão das construçōes, não chegavam a ser "pedreiros" propriamente ditos, ou seja, näo chegavam a trabalhar manualmente. Mas mesmo essa autoria "intelectual" dos monges é objeto de contestação. V., p. ex., Cecil STEWART, Early Christian, Byzantine and Romanesque Architecture, Simpson's History of Architectural Development, Londres, 1954, pp. 131-132 e Arnold HAUSER, Historia Social de la Literatura y el Arte, Madrid, 1968 (Traduzido do alemão). Vol. 1, pp. 229 sqq.

(21). - "Á la vérité, il est permis de supposer que de nombreux documents furent détruits par certains frères scrupuleux em 1720, et qu'ils peuvent avoir détruit de la sorte les vieux rituels qui seraient maintenant pour nous d'un intérêt considérable". L. VIBERT, p. 10 .

(22). - L. VIBERT, p. 12, menciona uma boa dezena de características particulares envolvendo os seguintes aspectos: conexão com atividade profissional definida (ou pelo menos um simulacro de conexão), constituição regulamentar, normas de admissão de candiđatos bem como as pré-condições, signos secretos e senhas, história tradicional, traje cerimonial, ritual bem preciso, deveres mútuos dos membros, simbolismo elaborado e periodicidade das reuniōes.

(23). - Maiores detalhes fogem aos limites deste trabalho, objeto de grandes desenvolvimentos em L. VIBERT, passim e sobretudo às pp. 39-73 e Th. VAROLI $F^{\circ}$, passim, sobretudo pp. $51-226$. Vide igualmente as observações espirituosas e mesmo sarcásticas de A. LANTOINE, pp. 3-5 e 51-54. V. tb. R. F. GOULD, pp. 1-19. 
pretado como uma irreverência de profano é oportuno dar a palavra a autoridades acima de qualquer suspeita nesse sentido:

“... we shall hardly err if we attribute what similarity there may be found to exist between the customs of the Essenes, the School of Pythagoras, and the Freemasons, to the spirit of brotherhood which has prevailed in all ages throughout the civilized world. The characteristics of any fraternity - all of whose members are engaged in the same pursuit and votaries of the same creed - will, on a close view appear to be brotherly love, charity, and that secrecy which gives them their exclusiveness. Hence, between all societies, ancient or modern, which are united by a fraternal tie, these "remarkable coincidences" will be found to exist" (24).

Ou ainda:

"L'argument sur lequel la plupart des spéculations nonscientifiques de tous les écrivains anciens (et trop d'écrivains modernes) sont basées, c'est le dangereux argument de l'analogie ou de la similitude. Et tout ce qu'on a écrit de faux sur la Maçonne-. rie est dû à l'enthousiasme des chercheurs qui ont salué comme preuves de la Maçonnerie toutes les occasions offrant quelque similitude; ceux qui ont cru démontrer l'existence de l'Ordre par l'initiation druidique, par les secrets des sauvages australiens ou par la sculpture de nos instruments de travail dans une catacombe; ceux qui attribuent notre rituel aux dieux des Pyramides et qui voient déjà notre costume de cérémonie dans les jardins de l'Eden" (25).

E mais adiante, tratando de um caso particular de similitude:

"L'idée d'initiation est fort commune à tous les stages de la pensée humaine. Au fait, nous avons deux initiations distinctes: notre troisième degré est réellement une initiation de type différent. Par ailleurs, il est évident que si nous connaissons la forme de toute cérémonie particulière à l'antiquité, les auteurs de notre rituel ont fort bien pu la connaitre aussi, et l'imiter; si bien qu'aucun argument de similitude n'est plus valable. Par contre, si nous n'avons aucun renseignement de détail, l'argument de similitude est ainsi exclus; quant à la simple analogie de l'existence d'une cérémonie, elle ne constitue aucun argument" (26).

(24). - R. F. GOULD, p. 10.

(25). - L. VIBERT, p. 11.

(26). - Idem, p. 15 . 
Todavia, mesmo a partir de tão justas observações, negar, na constituição da atual Maçonaria, quaisquer influências anteriores às sociedades profissionais do fim da Idade Média, representaria, a nosso ver, um excesso de rigor crítico - e até mesmo uma volta às concepções historiográficas positivistas (o que não está documentado não existe...) - revelador mesmo de insuficiência de senso histórico. Como, para que um dado problema histórico fique elucidado é, por vezes, recomendavel partir de suas bases - o que julgamos ser o presente caso - mesmo correndo o risco de dar a impressão de divagar, examinaremos alguns pontos fundamentais relativamente ao papel do setor das construções no conjunto das atividades humanas.

Relembremos inicialmente que nas construções - sobretudo nas de um certo vuito, empregando materiais de manipulação mais delicada e técnicas mais elaboradas - encontramos uma das manifestações mais típicas da civilização, tão típica quanto a escrita e o uso de utensílios de metal. Trata-se de um dado elementar que, por isso, não merece insistência, mas, apenas para dar um exemplo, é na presença ou ausência de construções monumentais que encontramos um dos divisores de águas entre, digamos, as chamadas civilizações pré-colombianas (maias, aztecas e incas), de um lado, e as demais populações indígenas americanas. Disso resulta que quando a arte de construir de povos afastados uns dos outros, geográfica ou cronologicamente, apresenta em suas manifestações semelhanças, fato não muito raro (veja-se o caso das pirâmides egípcias e aztecas), o que pode ocorrer tambem em outros setores, como as táticas e armas de guerra ou gêneros literários, é sempre dificil estabelecer com precisão até que ponto se trata de simples coincidências ou frutos de uma influência cultural. Sem entrar no campo das hipóteses sobre se a evolução histórica dos fenômenos de civilização obedece a um mecanismo de monogênese (durante algum tempo foi popular a teoria que fazia dos egípcios a fonte inicial de todas as civilizações, mesmo as pré-colombianas: mas haverá ainda nos meios científicos alguem que leve em consideração uma tal elocubração?) ou poligênese, com manifestações independentes de fatos culturais da mesma ordem, mas, mesmo a adoção desta última posição não invalida a noção de um processo acumulativo nessa esfera. Aliás, se assim não fosse, que sentido teria o estudo de sociedades de períodos remotos? Um mero interesse comparativo? Dessas considerações deduz-se que, ainda que se deva renunciar à atribuição da origem precisa deste ou daquele elementos das técnicas de construção utilizadas pelos "pedreiros" medievais, não nos parece razoavel negar a função destes como mantenedores e cultivadores de um acervo de conhecimentos remontando a épocas muito recuadas. E 
evidente que uma tal observação se aplica a qualquer setor da cultura, mas, dada a complexidade da atividade construtora, é de se supor que aqui a continuidade deve ter sido particularmente acentuada, o que incluiria os famosos segredos operativos. Como os fenômenos de relacionamento social são elementos de cultura, tanto como as manifestações materiais, algo semelhante pode ter se verificado no que diz respeito às modalidades associativas adotadas pelos construtores e, embora uma insinuação dessa ordem possa soar como elocubração arbitrária, talvez o dificil enquadramento desse setor da mão-de-obra nos esquemas vigentes na Baixa Idade Média (guildas profissionais, corporações de ofícios, mesmo confrarias e fraternidades), tantas vezes notados pelos que cuidaram do problema, mesmo os não maçons, não deva ser desprezado como indício dessa nossa sugestão (27).

Nesse sentido, a manutenção das técnicas de construção em pedra durante a Idade Média não deixou de representar a sobrevivência de um segmento da herança da civilização antiga, ameaçada pela instalação dos bárbaros no Império Romano, já que os mesmos somente praticavam a construção com materiais de precária durabilidade, sobretudo a madeira. Em relação à Inglaterra anglo-saxônica - que merece, no contexto do presente trabalho, uma atenção diferenciada - essa técnica parece ter sofrido um eclipse particularmente acentuado, prolongando-se até à conquista normanda em 1066, pois, com exceção da "muralha de Offa" (Offa's Dyke), o uso da pedra parece ter sido bastante esporádico, com igrejas e palácios, e mesmo fortificaçōes, tendo como materiais de base tijolo e madeira (alem de indicações arqueológicas, a representação do palácio real na "Tapeçaria de Bayeux", p. ex., representa uma boa ilustração dessa tendência) . Todavia, a situação na parte setentrional da Europa Ocidental (em relação ao Mediterrâneo o panorama se apresenta sensivelmente diferente) não era radicalmente diversa e pode-se dizer que, mesmo em relação às igrejas, a generalização do uso da pedra é um fenômeno já deste milênio. E, portanto, na Inglaterra como no Continente verificaram-se tentativas reais de estimular a maçonaria (aqui usamos o termo no sentido estritamente operativo), havendo referências, é verdade que tardias e bastante duvidosas quanto à autenticidade, a privilégios concedidos por Carta pelo rei anglo-saxão Aethelstan em 926 aos seus peritos (28). Daí não é dificil compreender-se

(27). - Gwilym Peredur JONES, Building in Stone in Medieval Western Europe, in The Cambridge Economic History of Europe, Vol. II, Cambridge, 1952 , pp. 515 sqq.; R. F. GOULD, pp. 66 sqq.; B. E. JONES, pp. 58 sqq.; L. VIBERT, pp. 23-37; Bronislaw GEREMEK, Le salariat dans l'artisanat parisien aux XIIIe - XVe siècles, Paris - La Haye, 1968, p. 17.

(28) . - Elas constam do chamado MS. Regius, o mais antigo documento maçônico subsistente e que data do fím do século XIV. Cf. B. E. JONES, pp. 69 e sobretudo 83 sqq.; L. VIBERT, pp. 41 sqq. e 57 sqq. 
que, num clima social em que as manifestações de barbárie demonstravam tanta vitalidade, tendessem esses profissionais a se atribuir uma posição especial e se constituir em grupos fechados, hostis à divulgação de seus conhecimentos (29).

Neste ponto tocamos numa das características mais salientes e mais controvertidas da Maçonaria: a propensão ao segredo, explicavel tanto pelo carater de seu trabalho no plano estritamente profissional, quanto na sua função social. No que concerne ao primeiro ponto, sobretudo considerando tratar-se de uma época em que a diferenciação de funções era ainda muito limitada, impunha-se a necessidade do emprego de mão-de-obra não qualificada em larga escala, o que levava à preocupação do sigilo - existente a bem dizer em todos os ofícios - pelo desejo de evitar um aumento muito grande da concorrência (30). Como a prática da profissão, por outro lado, revestia-se de um carater itinerante, ao qual já aludimos mais de uma vez, que a diferenciava das demais, era normal que os seus cultivadores procurassem distinguir-se de forma segura, de molde a dificultar a infiltração de impostores, o que estimulou o desenvolvimento dos signos de reconhecimento (embora não se saiba com certeza se o mais típico deles - o aperto de mão especial - já era adotado). Visto que a solidariedade profissional tinha na assistência mútua uma de suas manifestações preferidas, pode-se supor que esse carater inter-regional - e mesmo internacional - das entidades maçônicas, mesmo na fase operativa, constituiu um dos principais atrativos para os elementos estranhos à ocupação (31) .

No plano da função social, sem negar a importância das construções civis e militares, que não cessou de aumentar nos últimos séculos da Idade Média, deve-se dizer que durante boa parte da trajetória da civilização, não apenas ocidental, mas tambem geral, os trabalhos arquitetônicos estiveram ligados sobretudo à expressão dos mais autênticos sentimentos religiosos, favorecedores ao mesmo tempo do esoterismo e do orgulho que, na Idade Média, no período da chamada "Cruzada das Catedrais" (32), levou os construtores a se classificarem co-

(29) . - R. F. GOULD, p. 71, refere-se a um bispo de Utrecht, assassinado em 1099 por um "pedreiro" por ter extorquido do filho deste, na sua ausência, o "mistério magistral" (arcanum magisterium) de lançar as fundações de uma igreja.

(30). - B. GEREMEK, op. cit., pp. 43 sqq. e 70 sqq.

(31). - P. NAUDON, pp. 26 sqq.

(32) - - A expressão é usada com frequência por J. GIMPEL, op. cit., sobretudo às pp. 33 sqq., para designar o período em que a arquitetura religiosa medieval atingiu seu mais intenso florescimento, ou seja, os séculos XI a XIII. 
mo os artífices da Opus Dei (33), ou edificadores das "Casas de Deus".

E irrefutavel que a arquitetura religiosa, expressão dos sentimentos de fé coletivos, nem sempre ocupou o primeiro lugar no conjunto das atividades de construção e, muito menos ainda, nem sempre foi a expressão sem segundas intenções dos sentimentos religiosos mais autênticos. Na Atenas de Péricles, na Roma de Augusto ou na Itália do Renascimento, por exemplo, as inúmeras construções de destinação religiosa traduziram muito mais intensamente uma inclinação indisfarçada pela ostentação do talento artístico dos seus criadores e do bom gosto dos seus promotores, do que propriamente servir como testemunho da fé coletiva e não é por acaso que se tratou de fases em que os que por elas eram responsáveis foram objeto de verdadeiro culto como "artistas". Em outras épocas, porem, os encarregados dessas tarefas se contentaram mais humildemente com a condição de artezãos, sem prejuizo, aliás, da manifestação franca de eventuais sentimentos de orgulho pelas suas realizações particularmente bem logradas. Nessas fases, o cultivo de tendências esotéricas, com a atribuição de significado místico às formas empregadas, foi particularmente intenso e foram tambem momentos em que as fronteiras entre a concepção e a realização se mostraram assaz imprecisas. Em compensação, nos períodoṡ em que a intenção particularmente artística predominou sobre o fervor religioso, a distinção entre concepção e realização tendeu a ser sublinhada, com o artista idealizador relutando em participar da parte artezanal. No caso da transição da Maçonaria operativa para a especulativa, correspondente ao período que se segue imediatamente ao Renascimento, acreditamos que a nostalgia dos valores tornados anacrônicos na prática profissional, e que já tinham perdido a parte mais substancial de sua viabilidade, dada a predominância irreversivel do arquiteto formado nas Academias, contribuiu decisivamente para a metamorfose das sociedades maçônicas, desencadeando a transposição dos segredos operativos para um plano puramente simbólico e mesmo alegórico.

Todavia, seria errôneo ver na conduta das sociedades maçônicas um cunho exclusivamente retrógrado, baseado em valores anacrônicos e superados, visto que a orientação da Maçonaria é bastante polivalente $e$, inclusive, como frisamos, o que se verificou foi uma metamorfose e não uma simples fixação em relação aos citados valores, esvaziados por completo de seu carater operativo. Não que as facetas retrógradas e, às vezes, mesmo obscurantistas, tenham estado sempre ausentes: até o século passado havia círculos maçônicos que enalte-

(33). - J. GIMPEL, passim e sobretudo pp. 51 sqq., 99 sqq. e 130 sqq., combate vigorosamente e com argumentos substancialmente documentados a idóia de um anonimato dos bâtisseurs des cathédrales. V. tb. A. HAUSER, op. cit., Vol. 1, pp. 230 sqq. 
ciam as sete artes liberais medievais, tratando-as como "um mistério incomunicavel a profanos, quer porque tivesse relação com o número sete, quer porque, de acordo com os "entendidos", podiam representar os degraus que levam o maçon até o trono do Oriente.... A verdade é que as sete ciências ou artes eram tudo quanto conheciam os antigos..." (34). Outros exemplos poderiam ser acrescentados, mas, em compensação, pode ser alegado que tendências progressistas aí tambem encontraram guarida. No plano intelectual, p. ex., a atração exercida pela Instituição sobre os alquimistas não deixa de ser significativa, não obstante o fato de as suas atividades comportarem inegavelmente propensões charlatanescas. Mas, mesmo eles estavam conformes com o processo histórico global da civilização ocidental, pois, assim, como o desenvolvimento do espírito crítico representa o aspecto racional da progressiva laicização cultural, as manifestações ocultistas ilustravam seu lado irracional, pois, embora com frequência a alquimia seja apresentada como uma expressão típica das concepções científicas medievais, ela deve na verdade ser encarada muito mais como uma manifestação de modernidade. Concluindo, sem dúvida a Maçonaria tendeu a incorporar mais os elementos ocultistas e sim. bólicos do que os experimentais da alquimia, mas mesmo assim, temos aí um exemplo de sua luta pela afirmação de valores laicos e de resistência à censura de origem eclesiástica, que, somada a posições de tolerância religiosa, explica as frequentes condenações pontifícias (35).

Isto porque, em relação à sua atuação externa, durante períodos bastante longos a Maçonaria esteve na vanguarda nos combates por maior justiça social e, sobretudo, maior liberdade política (36). Essa ambiguidade pode ser explicada pela paradoxal contradição que marcou a sua evolução na fase pré-especulativa. Conservadora ao ponto da esclerose operativamente, o que contribuiu, como vimos acima, para o seu esvaziamento progressivo nesse plano, e inovadora no plano social, inclusive, como veremos mais adiante, com uma ação que ainda na fase operativa, obviamente guardadas as devidas proporçōes, prefigura à dos sindicatos anglo-saxões, não diremos atuais, mas os do

(34). - Th. VAROLI Fo, pp. 245-246.

(35). - Sobre o problema da infiltração da alquimia e do ocultismo nos meios maçônicos v. L. VIBERT, pp. 112 sqq.; B. E. JONES, pp. 117 sqq.; P. NAUDON, pp. 75 sqq.

(36). - Tal se aplica particularmente às comunidades obedientes aos preceitos ingleses, já que o chamado "rito escocês" tendeu para posições mais conservadoras e para uma orientação mais aristocrática. Particularmente esclarecedoras são as páginas dedicadas ao tema por $\mathrm{A}$. LANTOINE, pp. 21-36 e 79-224, que ainda acentua o quanto esse conflito de orientações agitou os meios maçônicos da França, em conexão com as convulsões políticas desse país no século XVIII. Mas, a participação das sociedades maçônicas nos eventos políticos contemporâneos em geral tem sido objeto de controvérsia, manifestando-se em certos círculos reservas ao que chamam de "teoria conspirativa" da história da Maçonaria. V. P. NAUDON, pp. 52 sqq. 
século passado e que mais tarde continuou num plano diferente, predominantemente político. .

Mas, voltando à questão do sigilo, se em relação à atual Maçonaria especulativa não há dúvida quanto ao fato de ele se referir mormente ao ritual, em relação à operativa as divergências são consideráveis entre os estudiosos. Há os que defendem a tese de que se tratava essencialmente de "truques do ofício", sem qualquer outra implicação (37), mas outros, sobretudo os mais antigos, adotam uma atitude mais cautelosa, em vista do silêncio das fontes (38). Dada a propensão medieval para juramentos, símbolos e outros traços ritualísticos acreditamos ser altamente improvavel que o segredo girasse exclusivamente em torno de problemas técnicos, especialmente considerando-se a inclinação da profissão a se atribuir uma posição à parte entre os ofícios, estabelecendo normas rígidas de conduta para seus membros e condições rigorosas para a admissão de novos associados, inclusive a interdição da aceitação de dependentes (em inglês bond's men) (39). $\mathrm{Em}$ todo caso, é inegavel que à medida que nos aproximamos do $\mathrm{Re}$ nascimento, com o esvaziamento do carater privilegiado do ofício o desenvolvimento de tendências esotéricas e especulativas foi se acentuando, atingindo plena configuração bem antes da fundação da "Grande Loja Inglesa" em 1717, o que autoriza uma interrogação: seria provavel que essa evolução tivesse tido curso indepencuadas da Maçonaria operativa?

A resposta a essa questão ficará mais facil se levarmos em conta alguns pontos básicos:

1). - O carater fechado não era exclusivo do setor das construções, existindo em maior ou menor escala em todas as associações profissionais, inclusive manifestando-se de forma bem concreta na acentuação das tendências monopolistas das Corporações de Ofícios no fim da Idade Média, fato a ser atribuido à contração generalizada da economia então verificada (40).

(37). - J. GIMPEL, pp. 6 sqq. e sobretudo 121 sqq. Essa opinião é compartilhada por B. E. JONES, pp. 66 sqq., que, inclusive, vê no termo mystery muito usado uma adaptação desajeitada do termo francês mestière (profissão), mas discute às pp. 88 sqq. com simpatia a idéia de Gould da formação de um núcleo esotérico no interior do ofício às pp. 88 sqq. V. tb. B. GEREMEK, pp. 74 sqq.

(38). - L. VIBERT, pp. 16 sqq., p. ex., admite constituir o rito atual a continuação de ritos medievais. R. F. GOULD, pp. 106 sqq., julga documentadas tendências à especulação hermética no século XV.

(39). - O MS. Regius, comprovadamente o mais antigo documento interno da ordem, é bastante explícito quanto a essas matérias. V. R. F. GOULD, p. 67; B. E. JONES, pp. 82-85; L. VIBERT, pp. 69 sqq.

(40). - Em relação ao setor de construçōes é significativo que não obstante a dificuldade para a constituição de guildas segundo o figurino então cor- 
2). - A mobilidade particularmente pronunciada dos profissionais da construção dificultou, de um lado, o seu agrupamento em Guildas ou Corporações e, de outro, implicou em relacionamento à distância mais frequente do que na maioria das outras ocupações. As fortificações cristãs na Terra Santa constituem um bom exemplo de como sua atividade podia se exercer em lugares bem afastados e, embora se possa discutir o quão intenso era o intercâmbio entre os "pedreiros" dos vários pontos da Cristandade, não cabe colocar em dúvida a sua existência, sendo ademais certo que fossem mais constantes do que na maior parte dos outros ofícios.

3). - Ainda que, como já sublinhamos anteriormente, seja exagerado imaginar que os mestres em construções pudessem ser considerados como arquitetos no sentido moderno, ou mesmo antigo (queremos nos referir à Antiguidade greco-romana), com toda a formação intelectual que o termo implica, seria tambem errôneo classifica-los como meros práticos, visto estar suficientemente documentado o fato de os seus conhecimentos teóricos terem sido bastante extensos (41) e, dado que tudo que dizia respeito a números, medidas e formas geométricas na Idade Média era objeto de especulações místicas, não vemos como os maçons operativos pudessem se subtrair a elas, restringindo-se seu segredo a "truques do ofício" (42). Por todas essas razões julgamos provavel que as associações maçônicas operativas eram entidades mais fechadas que as congêneres de outras profissões e, nesse contexto, com afinidade mais acentuada com seitas secretas.

rente - devido à mobilidade característica do ofício e ao pequeno número de elementos permanentemente estabelecidos em cada cidade -, é a partir do século XIV que as referências a esse tipo de associação se façam presentes na Inglaterra e França. Mais interessante ainda é o caso da Alemanha onde os Steinmetzen (talhadores de pedra) organizaram no século XV uma confederação com ramificações em todas as regióes. V. L. VIBERT, pp. 96 sqq.; B. E. JONES, pp. 109 sqq.; G. P. JONES, Building in Stone..., Cambridge Economic History..., Vol. II, pp. 515 sqq.

(41) . - O documento mais expressivo nesse sentido é o caderno de notas de Villard de Honnecourt, construtor picardo do fim do século XIII. J. GIMPEL, pp. 105-143, dedica-lhe todo um cap. V. tb. C. STEWART, Simpson's History of Architectural Development, Vol. III: Gothic Architecture, Londres, 1961, pp. 80 sqq. A. MARTINDALE, Gothic Art, Londres, 1967, pp. $69-70$.

(42). - Segundo a história lendária da Confraria, narrada pelo chamado MS. Cooke, Edwin, filho (sic) de Aethelstan, ao nela ingressar como "irmão aceito" (vide acima, nota 15) o fez por saber, "tanto quanto os próprios maçons, que a Maçonaria era a aplicação prática da geometria. Eis porque discutia com eles, pedia-lhes conselho, e juntava a seus conhecimentos teóricos (especulativos) a experiência dada pela prática. Era, dizem, um verdadeiro mestre em teoria especulativa e amava muito a Maçonaria e os Maçons". Citado por L. VIBERT, pp. 78-79. Mais interessante ainda, o termo "especulativo" já se encontra no próprio MS. Cooke, aplicado ao referido Edwin. 
Assim, vemos que, em virtude das lacunas na documentação, situado em termos genéricos, o problema da origem da Maçonaria desautoriza conclusões categóricas, exigindo um tratamento bem matizado. Mas, há um último ponto que não tem sido devidamente levado em conta em sua abordagem, sobretudo na historiografia mais especificamente maçônica, isto é, as obras escritas por maçons e destinadas primordialmente aos maçons, o que se entende, em vista da preferência de seus autores pelos aspectos éticos: a significação econômica das atividades de construção (43). Se em nossa época - apesar das multi-nacionais, da indústria pesada e da produção em série de bens de consumo - o comportamento do setor das construções ainda é fundamental para a avaliação das tendências econômicas, o que se dirá então dos períodos anteriores à chamada Revolução Industrial? Maior do que nos tempos modernos pois, então, apresentavam as grandes manufaturas uma concorrência significativa, enquanto na Idade Média as edificações se configuravam nitidamente como "a primeira, quase a única indústria" (44) de base. Com efeito, a complexidade das operações envolvidas fazia com que as construções se destacassem

“.. par sa fonction de stimulant économique. La production en grand de matières premières (pierre, bois, fer), la mise au point de techniques et la fabrication d'un outillage pour l'extraction, le transport, l'érection de matériaux de taille et de poids considérables, le recrutement de la main-d'oeuvre, le financement des travaux, tout cela a fait des chantiers de construction (et pas seulement des cathédrales mais aussi des innombrables églises de toutes dimensions, des bâtiments à usage économique: ponts, granges, halles, et des maisons de riches de plus en plus souvent construites en pierre)..." (45).

Situado o papel da indústria de construções no conjunto da vida econômica do período, poderemos admitir a priori que qualquer modi-

(43). - Restringindo-nos ao período medieval G. P. JONES, Building in Stone..., pp. 493-494, levanta algumas questões nesse sentido, mas o restante do canítulo mal chega a corresponder ao então anunciado. Em contrapartida, algumas das questões fundamentais (o peso da indústria de construções no conjunto da economia medieval, o reflexo das flutuações do conjunto da economia sobre o setor das construçóes, variaçóes no padrão da construçẫo em função das tendências gerais da economia etc.) nem sequer são aventadas. Aliás, trata-se de um campo em que a ausência de trabalhos significativos não se limita ao período pré-estatístico, já que em relação aos tempos modernos a situação é idêntica.

(44). - J. LE GOFF, La Civilisation de l'Occident Médiéval, Paris, 1965 , p. 187 V. tb. pp. 275 sqq.

(45) . - J. LE GOFF, op. cit., p. 87. Sublinhemos que o autor se refere ao período posterior ao ano 1000 . 
ficação na tendência desta última, quer no sentido da expansão, quer no da contração, se refletiu no comportamento da primeira e reciprocamente. Ora, por volta do ano 1000 há uma significativa coincidência entre um florescimento extraordinário da atividade construtora e uma renovação generalizada não somente da economia mas que se fez presente em todos os setores da sociedade ocidental (político-militar, cultural, literário, filosófico, etc.). Fatores externos (cessação das invasões) e internos (incremento demográfico, aumento da estabilidade interna graças à "Paz de Deus", inovações técnicas etc.) podem ser salientados, mas, o que impressiona é a generalidade do processo, envolvendo inclusive aspectos psicológicos, tais como a certeza, enfim, da superação do milênio, sem que se verificasse o fim do mundo (46) . O cronista Raul Glaber associa de forma inequívoca, ainda que não inteiramente explícita, o impulso construtor ao fenômeno numa passagem, aliás, das mais célebres na historiografia medieval:

"Ao aproximar-se o terceiro ano que se seguiu ao ano mil, viu-se por toda a terra, mas sobretudo na Itália e Gália, renovar-se as basilicas das igrejas; ainda que a maioria, assaz bem construidas, disso não necessitassem, uma rivalidade conduzia cada comunidade cristã a possuir uma mais suntuosa do que as outras. Era como se o próprio mundo se tivesse sacudido e, despojando sua velhice, tivesse se revestido por toda parte com um manto branco de igrejas". (Histórias, L. V, cap. 5) (47).

Considerando dever-se essa passagem a um coevo, adquire ela grande significação e, entre outros menos importantes para as nossas preocupações do momento, queremos chamar a atenção para dois pontos: a importância dada na época ao movimento de edificação de igrejas a canalizar o melhor do potencial coletivo criador do período e o espírito de emulação que levou, de um lado, à intensificação na

(46). - G. DUBY, L'An Mil, Paris, 1967, (Col. "Archives"), faz a ressalva de que um tal mecanismo somente pode ser aferido de forma indireta das fontes do período, sistematicamente mudas ao tema: a primeira referência explícita ao ano 1000 como um marco trágico, de Sigeberto de Gembloux, é de mais de um século posterior (p. 33). Todavia, Raul Glaber associa o fim dos temores e uma espécie de Primavera do Mundo à passagem do milésimo aniversário da Paixão, autorizando a suposição de que tinha havido um adiamento na expectativa de consumação das profecias apocalípticas, o que subentende a crença nas mesmas, explicando-se a ausência de referências pelo temor de que elas contribuissem para a efetivação dos desastres referidos nas previsões (p. 183).

(47) . - Citado por G. DUBY, op . cit., p. 197, (os grifos são nossos), - qual acrescenta: "Lorsque Glaber évoque cette "blanche robe", il n'use pas seulement d'une admirable metaphore. Il veut signifier que la chrétienté dépouille alors le vieil homme, adhère au parti du bien pour lutter contre les puissances de perversion, qu'elle s'apprête au nouveu baptême, qu'elle revêt la robe nuptiale pour s'approcher du banquet de son Roi". 
atividade construtora e, de outro, ao desejo de cada comunidade de superar tanto nas dimensões quanto na riqueza da decoração às igrejas das demais, impulso competitivo que com o tempo conduziu à erecção de catedrais gigantescas mesmo em cidades de limitada importância, como, p. ex., Amiens ou Chartres. Não podemos deixar de sublinhar que, como argumento a reforçar considerações anteriores, numa tal atmosfera os profissionais peritos em tais obras deveriam muito provavelmente sentir-se como ocupando um lugar realmente à parte na sociedade, o que talvez já tenha contribuido para dar às associações um carater especial. Mas, alem disso, a grande demanda de mão-de-obra qualificada do setor certamente colaborou para que nele inexistissem problemas quanto à obtenção de colocação e para que a sua remuneração se situasse num nivel elevado (48), o que, possivelmente, constitui uma das razóes para a pobreza de referências aos "pedreiros" e, sobretudo, a suas entidades. Isto porque é próprio dos períodos de expansão, caracterizados pelo dinamismo da atividade econômica, o amortecimento das tensões nas relações econômicas, sociais e políticas entre empregadores e empregados, contratantes e contratados, governantes e governados etc., o que pode ser apontado como um dos fatores prováveis do citado silêncio das fontes, ao lado de outros, como as destruições do tempo e a falta de hábito de registros de controle da parte dos empregadores.

Essa expansão, bem delineada a partir das alturas do ano 1000 , manteve-se de forma bastante estavel, até pelo menos, às últimas décadas do século XIII. Sobre seus mecanismos existem divergências entre os historiadores, mas há um consenso majoritário no sentido de atribuir ao crescimento demográfico um papel chave, resultando como corolário a conclusão de ter o mesmo importância fundamental na reversão de conjuntura verificada a partir do final do século XIII e início do XIV, com sintomas de estagnação que acabaram assumindo o aspecto de uma depressão generalizada, pontuada por desastres financeiros representados por grandes falências bancárias, sintoma de mal-estar econômico; crises de abastecimento suscetíveis de provocar altos índices de mortalidade, como a penúria que nos anos 1315-1317 assolou a parte setentrional da Europa; violentas epidemias tendo na Peste Negra de 1348 o seu protótipo perfeito, vitimando em curto espaço de tempo cerca de um terço da população européia; aumento de

(48). - Mas, as variações salariais podiam ser realmente significativas. No início do século XIV (já passada, por conseguinte, a grande época das edificaçóes), nas obras do Castelo Caernarvon (portanto, numa construção militar) enquanto os "pedreiros" comuns ganhavam 2 shillings e 6 pence por semana, o respectivo mestre, Walter de Hereford, fazia jús a 2 shillings por dia. $\mathbf{G}$. $\mathbf{P}$. JONES, Building in Stone..., Cambridge Economic History..., Vol. II, p. 507. 
virulência nos conflitos bélicos, tendo nas devastações da Guerra dos Cem Anos seu exemplo clássico, etc. .

Visto que em outro local já tratamos sobejamente do problema (49), somente nos cabe no momento examinar as manifestações dessa depressão no setor das grandes construções em pedra e, ainda uma vez, verificamos que ele esteve bem sincronizado com a orientação geral do período. Em relação à edificação de grandes catedrais, que se constituiu no resultado mais espetacular do boom consecutivo ao ano mil, há uma quebra brusca de impulso a contar do final do século XIII. Evidentemente, essa tendência comporta exceções e, assim, a gigantesca catedral de Milão foi iniciada somente em 1385, mas a fase da "emulação recordista" pode ser dada como encerrada com o desabamento da abóboda da catedral de Beauvais em 1284, concentrando-se, mais realisticamente, os esforços dos Capítulos na conclusão (50) e conservação (51) das existentes, com os novos empreendimentos rareando progressivamente.

A partir da Peste Negra o fenômeno acentua-se e, inclusive, a mudança estilística que se verifica na evolução do gótico com o desenvolvimento do flamboyant continental, que tem no perpendicular o seu equivalente inglês, é bastante significativa a esse respeito. Naturalmente, a ornamentação mais carregada dessa fase deve ser atribuida a uma mudança nos gostos, mas isso parece-nos constituir somente uma parte do problema, se considerarmos que as construções nesse estilo contrastam com as do gótico clássico pelas suas dimensões sensivelmente mais modestas e pela utilização em maior escala dos recursos da alvenaria (52), autorizando a suposição de que essa sobrecarga ornamental pode ser explicada igualmente pelo desejo de compensar a sua deficiência em monumentalidade. Alem disso, não obstante terem, tanto o flamboyant continental quando o perpendicular inglês,

(49). - Victor DEODATO DA SILVA, A Legislação Econômica e Social Consecutiva à Peste Negra de 1348 e sua Significação no Contexto da Crise do Fim da Idade Média, São Paulo (no prelo).

(50) . - As proporções das construções eram de tal ordem, inclusive em relação às disponibilidades financeiras, que as obras se arrastavam por séculos. V. J. GIMPEL, pp. 48 sqq. e 181 sqq.

(51). - Não sem exagero, J. LE GOFF, p. 275, atribui a necessidade de reformas ao fato de as construções serem "tecnicamente de má qualidade", de onde a necessidade de "consertar, substituir e refazer constantemente". Na verdade são excepcionais as obras que podem dispensar cuidados de manutenção (haverá muitas outras alem das grandes pirâmides, não somente as egípcias mas tambem as da América?) e somente um estudo comparativo sistemático, inclusive com constituição de estatísticas, poderia determinar se as produções medievais eram realmente muito piores tecnicamente do que as de outros períodos.

(52) . - C. STEWART, Simpson's History..., Vol. III, Gothic Architecture, pp. 100-101 e 127 sqq. 
produzido algumas obras encantadoras, não ocorreria a ninguem, acreditamos, atribuir-lhes importância comparavel à das grandes criações do gótico clássico, o que pode ser explicado por uma cesura tambem no plano espiritual.

Pois, com efeito, se as nossas preocupações do momento impelem-nos a realçar os aspectos materiais, muito longe estamos de defender a idéia de que as grandes catedrais dos séculos XII e XIII devam ser apreciadas só, ou mesmo preferencialmente, pelas suas grandes proporções, e as igrejas dos séculos XIV e XV (falamos em igrejas porque as novas catedrais foram relativamente raras e, quando existiram, não se revelaram muito menores - veja-se o caso já citado de Milão - do que as do período anterior) criticadas em virtude de suas menores dimensões. Na verdade, as grandes realizações da época que alguns historiadores não hesitam em qualificar como "Idade Média Clássica", constituem a expressão integral de uma conjuntura de equilibrio duradouro, mesmo que estabelecida sobre bases frágeis e assentada certamente sobre inúmeras injustiças, enquanto as criações do fim da Idade Média refletem uma crise prolongada, inclusive de substância. Essa crise se manifesta no plano doutrinário e intelectual pela condenação das bases mesmas do tomismo, confundido com averroismo, pelo bispo de Paris, Estevão Tempier, em 7 de março de 1277 (53), provocando um forte e duradouro mal-estar nos meios universitários. O desfecho da luta entre Felipe-o-Belo e Bonifácio VIII, por outro lado, ao levar à transferência da sede do Papado para Avinhão, cercou os meios eclesiásticos de uma opinião pública crescentemente cética e rompeu definitivamente o impulso religioso que possibilitou o extraordinário desenvolvimento anterior da arquitetura eclesiástica.

Voltando, enfim, aos profissionais em construção, deduz-se que a sua situação deve ter-se deteriorado progressivamente. Sem dúvida, a arquitetura religiosa não constituia o seu único campo de atividades e a queda da religiosidade no fim da Idade Média foi paralela a um incremento dos valores laicos, com a multiplicação de construções de carater civil, tais como palácios, mansões e edifícios públicos, mais suntuosos do que anteriormente era de regra, mas, alem de ser duvidoso que elas tenham compensado inteiramente a queda no movimento de erecção de grandes catedrais, tratava-se de obras empreendidas dentro de um espírito diferente e que, ainda por cima, não implicavam na utilização plena dos conhecimentos técnicos de seus responsáveis. Dessa situação resultou uma mudança no que concerne ao acervo de segredos operativos: de ativos, isto é, constantemente colocados em

(53) - J. GIMPEL, pp. 10-11. Para maiores detalhes v. Aug. FLICHE-V. MARTIN, Histoire de l'Eglise..., Vol. 13: Le mouvement doctrinal du XIe au XIVe siècle, por $A$. FOREST, F. VAN STEENBERGHEN e $M$. DE GANDILLAC, Paris, 1956, pp. 320 sqq. 
prática, foram eles se tornando passivos, ou seja, conservados apenas teoricamente. Temos aí, seguramente, uma das razões pelas quais os arquitetos renascentistas e de períodos posteriores tenham se mostrado incapazes de dominar certas técnicas medievais de construção, visto que a sua formação era radicalmente diversa, obtida em Academias obedientes a uma linha de ensino que, premeditadamente, ignorava as realizações góticas, visando filiar-se diretamente à tradição greco-romana. Mas, voltando ao plano material, sofreram os pedreiros-mestres um novo golpe com a redução drástica nas construções de grandes muralhas urbanas (54), é verdade que compensada pelo florescimento de fortificações em pequenas cidades e lugarejos, em virtude da intensificação das atividades bélicas, sobretudo na França (Guerra dos Cem Anos) e na Itália (rivalidades entre as repúblicas urbanas).

Todos esses fatos explicam que os "pedreiros", assim como ocorreu com a maioria dos ofícios, acentuassem o carater monopolista de suas associações profissionais. Nos cem anos que se seguiram à eclosão da Peste Negra atingiu a contração o seu ápice, provocando uma forte deterioração das relaçõès sociais, econômicas e políticas, bem exemplificada pela Jacquerie de 1358, pela revolta geral dos trabalhadores ingleses de 1381 e por um sem número de sedições rurais e urbanas de proporções variáveis que marcaram o período. Esses movimentos comprovam a atmosfera de mal-estar profundo e generalizado, explicavel pelo fato de às tendências à depressão se somar uma crise aguda de mão-de-obra decorrente da mortalidade provocada pela epidemia e suas numerosas reincidências, daí resultando oscilações bruscas nos preços e uma alta violenta dos salários, ocasionando protestos gerais aos quais os poderes públicos procuraram atender através de uma série de medidas legislativas visando ao controle de preços e salários, alem de determinações de combate à ociosidade e de regulamentação das relações entre empregadores e assalariados objetivando melhor distribuir a mão-de-obra disponivel.

Não se deve, contudo, concluir que por toda a Europa Ocidental a reação das autoridades apresentou a mesma intensidade e idêntico grau de sistematismo. Nas unidades políticas de menor porte - nas repúblicas italianas e principados alemães, p. ex. - somente se verificaram providências esporádicas, enquanto na maioria das grandes monarquias a ação se restringiu a expedientes de momento, abando-

(54). - R. S. LOPEZ e H. A. MISKIMIN, The Economic Depression of the Renaissance, The Economic History Review, 2nd series, T. XIV, 1962, pp. 414 sqq. A essa diminuição não deve ser atribuida uma significação econômica pois, nas condições de segurança da época, tratava-se de providência que, quando necessária, não podia deixar de ser adotada, residindo a sua explicação numa queda ou, pelo menos, estagnação demográfica. 
nados com o correr do tempo (55). Nesse sentido a grande exceção foi representada pela Inglaterra, onde o "Estatuto dos Trabalhadores" de 1351 , precedido por uma Ordenação (ato real promulgado pelo rei, com base apenas no parecer do Conselho Real e sem aprovação do Parlamento, obrigatória no caso dos "estatutos") em 1349, somente foi oficialmente abolido em 1563 por Isabel I, quando a ele já tinha sido adicionada uma abundante legislação. Considerando-se ter a vigência dessa legislação coincidido em grande parte com um período de prolongada depressão econômica, compreende-se que as relações de trabalho tenham estado cercadas de um clima de tensão contínua, a qual, entre outros reflexos que no momento não vem ao caso examinar, teve uma influência consideravel sobre a conduta dos praticantes dos ofícios ligados à construção.

A Ordinance de 1349 sequer chega a mencionar expressamente os trabalhadores categorizados das construções - referindo-se apenas aos carpentarii (carpinteiros), cementarii (pedreiros de alvenaria) e tegularii (cobridores de casas) - , mas compreende-se que eles estão incluidos na expressão et quicumque alii artifices et operariis (e quaisquer outros artesãos e trabalhadores), aos quais é imposto o salário vigente antes da epidemia (56), enquanto o Statute de 1351 se limita a estabelecer tetos salariais precisos, no caso dos maistres-maçons de quatro pence diários (57), sendo certo que, quanto aos chefes de canteiro essa importância constituia somente parte do pagamento, já

(55). - Essa legislação é objeto de estudo sistemático e detalhado em V. DEODATO DA SILVA, op. cit., passim. Para o pessoal de construção v. tb. R. F. GOULD, pp. 65 sqq.; L. VIBERT, pp. 85 sqq.; B. E. JONES, pp. 36-37.

(56). - V. DEODATO DA SILVA, p. 85.

(57). - Idem, cifras indicadas no apêndice. A esse respeito B. GEREMEK, pp. 132-133, afirma: "... le statute of labourers anglais de 1349, ordonne que les salaires soient fixés au niveau pratiqué vingt ans auparavant...". Parece-nos haver um lapso, senão vejamos: A Ordenação de 1349 reza: "... consueti sunt prestari anno regni nostri Anglie vicesimo, vel, annis communibus, quinque vel sex proximo precedentibus". Th. RYMER, Foedera, conventiones, litterae etc. . . . acta publica. ... Londres, 1816-1869, T. 1, p. 198; por outro lado, o "Statute" de 1351 estabelece "... que tieux manieres des servants, sibien hommes come femmes, fussent tenuz de servir, receyvantz salaries et gages accustumez es lieus ou ils deveront servir, lan du regne de dit nostre Seigner le Roi vintisme, ou cynk ou sis annz devant..." THE STATUTES OF THE REALM..., Londres, 1810-1828, Vol. I, p. 311. Quanto à segunda referência, a redação, tanto do documento latino quanto do vernáculo deixa dúvida (cinco ou seis anos antes da promulgação do documento? $\mathrm{Ou}$ antes do vigésimo ano do reinado de Eduardo III? Embora em nosso trabalho acima referido tenhamos optado pela primeira alternativa, a segunda nos parece agora ser a correta), mas quanto à primeira não há margem para qualquer hesitação, trata-se do vigésimo ano do reinado de Eduardo III (esta era uma forma de datação ainda em uso na Inglaterra na época), ou seja, 1346 e não vinte anos antes da promulgação do documento, ou 1329. 
que era costumeiro, em relação ao pessoal mais categorizado, um contrato especial, prevendo por vezes remunerações assaz elevadas (58), mas, sem dúvida, mais digna de destaque é uma estipulação contida no primeiro desses documentos e que, aludindo a todo tipo de mão-de-obra rural ou urbana, reza:

"Et habeant potestatem major et ballivi... ad inquirendum de omnibus et de singulis, qui contra in aliquo deliquerint et ad penam predictam, ad opus illorum, ad quorum sectam hujusmodi delinquentes convicti fuerint, levandum" (59).

O termo seita tem no caso um carater genérico e manifestamente designa associações ou grupos destituidos de personalidade jurídica, pois, se outro fosse o caso, teria sido usado um vocábulo mais preciso, deduzindo-se que os trabalhadores, dada a falta de representatividade das entidades corporativas legalmente reconhecidas, todas elas devidamente controladas pelos poderes públicos, procuravam clandestinamente articular a defesa de seus interesses. Poder-se-ia perguntar aié que ponto essa iniciativa foi tomada pelos vários setores profissionais $\mathrm{e}_{\text {: }}$ com efeito, de uma forma geral era o enquadramento corporativo na Inglaterra tão eficientemente exercido que pode-se duvidar da frequência de um tal comportamento. A questão fica melhor elucidada por ocasião do enforcement - ou seja da reiteração com carater de reforço - do Statute de 1351, verificado dez anos depois e quando a Inglaterra já sentia os efeitos da primeira reincidência da Peste Negra, qualificada como mortalité des enfanz, por ter incidido particularmente sobre as crianças de pouca idade, nascidas após a terrivel visitação de 1348 e, portanto, não imunizadas contra o mal (60):

"Et q'en ceste ordinance soient comprises sibien Carpenters et Maceons, come touz autres laborers servantz artificers; et que les Carpenters et Maceons preignent desore salarie par la journeie, et nemie par simaigne nen autre manere; et que les chiefs mestres des Carpenters et Maceons preignent le jour iij deniers et les autres iij ou ij deniers solonc qils vaillent: et que totes alliances et covignes des Maceons et Carpenters, et congregations, chapitres, ordinances et serementz entre eux faites ou affaires, soient desore anientiz et annulez de tout: Issint que chescun Maceon et Carpenters de quel condicion qil soit, soit arte, par son Mestre a qi il sert, de faire

(58). - Sobre o problema da remuneração dos responsáveis pelas grandes edificaçóes v. J. GIMPEL, pp. 69-85; B. GEREMEK, pp. 87 sqq.; G. P. JONES, Building in Stone..., Cambridge Economic History..., Vol. II, pp. $510 \mathrm{sqq}$.

(59) . - Th. RYMER, op. cit., p. 199. (O grifo é nosso).

(60). - V. DEODATO DA SILVA, p. 103. 
chescun overaigne que a appent affaire, ove de fraunche pere ou de grosse pere, et aussint chescun Carpenter en son degre; mes bien lise a chescun Seigneur et autre de bargainers et convenancer de lour overaignes en grosse ou tiels laborers et artificers quant leur plerra issin qils perfournent tiels overaifnes bien et loialment, selonc les bargaines et convenant ove eux ent faitz" (61).

Assim, fica claro que a atitude de resistência esteve longe de ser generalizada e que foi sobretudo característica do setor das construções, o que, aliás, é compreensivel, já que as suas peculiaridades anteriormente referidas (maior mobilidade, facultando evitar regiões onde o zelo das autoridades fosse muito rigoroso; frouxo enquadramento nos quadros corporativos, sendo que as guildas se constituiam em instrumento de controle por parte dos poderes públicos, sobretudo na Inglaterra; longa tradição de comunicações à distância, dando margem a que medidas na defesa do interesse do grupo fossem colocadas em prática inter-regionalmente) facilitavam sua adoção. Bastante interessante é tambem observar que esse comportamento começava a merecer restrições de outros círculos que não os oficiais, inclusive nos meios religiosos, sendo bem representativa uma crítica assaz severa partida do lider Lollard John Wyclif por volta de 1360 , ou seja, na mesma época do ato real acima transcrito:

"Eles conspiram conjuntamente para que nenhum homem de seu ofício aceite menos por dia do que combinaram entre si, mesmo que em boa consciência pudessem aceitar muito menos, e que nenhum deles deve empreender firmemente trabalhos que possam prejudicar os rendimentos de outros homens de seu ofício" (62).

E evidente que qualquer vinculação dessa atitude dos "pedreiros" com possíveis preocupações esotéricas é totalmente descabida, mas sua significação no sentido de desenvolver mecanismos de resistência às injunções externas não pode ser subestimada, sendo, no mínimo, altamente provavel que ela tenha acentuado as tendências do grupo ao uso de signos de reconhecimento mútuo, ao segredo e à complicação das condições de aceitação de novos membros, ao mesmo tempo em que colocavam o setor na vanguarda do movimento social. Por outro lado, tal tensão entre os elementos da profissão e as autoridades não se constituiu num episódio de curta duração, pois, se não há indícios de qualquer participação destacada dos mesmos na grande revolta de

(61). - THE STATUTES OF THE REALM..., op. cit., pp. 366-367.

(62). - Cit. por C. STEWART, Simpson's History..., Vol. II, Early Christian, Byzantine and Romanesque Architecture, p. 132. 
1381 - movimento de carater mais rural do que urbano - é significativo vermos Henrique VI em 1425, mais de meio século desde o enforcement de 1361, reiterando em Ordenação, a condenação às modalidades clandestinas de atuação, somente que, desta vez, a referência é restrita aos "pedreiros", sem envolver os carpinteiros como no documento anterior:

\begin{abstract}
"Visto que por congregações e confederações feitas anualmente pelos "pedreiros" reunidos em seus capítulos gerais (Generalx Chapitres Assemblez), o bom andamento e eficiência do "Estatuto dos Trabalhadores" são abertamente violados e rompidos, numa subversão da lei, e para grande prejuizo de todos os Comuns: nosso mencionado Senhor Rei desejando neste caso dar remédio, pelo conselho e decisão acima mencionados e por especial solicitação dos citados Comuns, ordenou e estabeleceu que tais capítulos e congregações não sejam mais daqui por diante levados a efeito; e se ocorrer que eles provoquem a reunião de tais capítulos e congregações, que os que disso se tornarem culpados sejam julgados como felões, e que todos os outros "pedreiros" que compareçam a tais capítulos e congregações sejam punidos com a prisão de seus corpos e sujeitos a multas e fianças conforme o desejo do Rei” (63).
\end{abstract}

Esta se constituiu na mais severa das medidas legislativas reais contra as violaçōes ao Statute of Labourers e merece destaque restringir-se à ação dos profissionais da construção, mas não foi a única, tendo sido precedida e sucedida por outras, a última das quais de 1531 , em que os masons são citados ao lado de praticantes de outros ofícios (64), devendo ser sublinhado o fato de que nestas reiterações mais genéricas do diploma legal de 1351 o tom é sensivelmente menos rigoroso. Aos poucos, as referências à resistência contra a legislação sobre o trabalho foram rareando e, no que diz respeito aos "pedreiros" isso se explica tanto pela progressiva superação dos desequilíbrios econômicos resultantes da depressão generalizada do fim da Idade Média, quanto pelas transformações verificadas no âmbito da cultura e da religião, onde, de um lado, a lenta mas contínua e segura infiltração dos ideais humanistas e da estética renascentista suscitou um desdem crescente pela bárbara "arte gótica", e, de outro, a difusão cada vez mais intensa das doutrinas reformistas resultou em repulsa a um estilo ligado à exaltação dos valores católicos numa de suas mais típicas expressões.

(63). - Cit. por R. F. GOULD, p. 93.

(64). - Idem, pp. 93 sqq. 
Os meios maçônicos naturalmente tambem foram agitados por essas novas tendências, mas tudo numa atmosfera mais pacífica, tendo por palco as Companies of Freemasons. A referência mais antiga à de Londres é de 1376, quando ela se confundia com as guildas profissionais comuns (65), mas ela sofreu algumas transformações que alteraram sua fisionomia no século seguinte e, em 1472, obteve um escudo de armas e seus membros passaram a promover barequetes privados com o comparecimento em uniforme (66), apresentando mesmo afinidade com os clubes, instituições estas que, observe-se, adquiriram exatamente na Inglaterra e a partir dessa época suas características mais típicas. Embora, inclusive sob esse aspecto assaz inofensivo, tenham se verificado algumas restrições dos poderes públicos, esse não é um ponto que mereça destaque, sendo preferivel ressaltar que a partir de então deve ter aumentado sua atração sobre os elementos estranhos à profissão, ficando mais amplamente aberto o caminho para a "Maçonaria de aceitação".

Chegando ao termo destas considerações pode-se constatar que, não apenas falta uma elucidação satisfatória à questão das origens da Maçonaria, mas que é mesmo improvavel que algum dia ela venha a existir, tendo em vista a reduzida probabilidade de vir a ocorrer ainda uma consideravel cobertura às lacunas apresentadas pela documentação. Numa tal situação é compreensivel que a atitude historiográfica positivista a que já aludimos - dentro da divisa de Foustel de Coulanges: pas de documents, pas d'Histoire - represente uma tentação quase irresistivel, e à qual sucumbiram inclusive muitos dos membros da Instituição que se debruçaram sobre seu passado - a obra de Lionel Vibert, tantas vezes citada nas notas, é um bom exemplo - mas seja-nos permitido manifestar a esperança de que este artigo tenha contribuido para evidenciar que essa solução não chega a ser inteiramente convincente.

Embora não se trate de uma constatação inédita, acreditamos que a noção de que a Maçonaria se constituiu no ponto de confluência de tendências das mais variadas origens, incorporadas em períodos os mais diversos - incorporação essa que, contudo, somente se verificou por haver condições propícias para tanto - ficou, por pouco que seja, mais reforçada. Um ponto em torno do qual, por outro lado, é incômodo fixar posição é aquele que diz respeito à possivel conexão entre a circunstância de a Maçonaria especulativa moderna ter nascido na Inglaterra - em que pese a significação de manifestações autônomas análogas em outros países, sobretudo na Escócia - e o fato de aque-

(65) - - R.F. GOULD, p. 105; G. P. JONES, Building..., p. 515.

(66) . - R. F. GROUL, pp. 108 sqq.; B. E. JONES, pp. 70 sqq. 
le país ter sido precisamente o que assistiu à luta mais pertinaz e prolongada dos poderes públicos para impor uma solução legal aos desequilíbrios econômicos e sociais decorrentes da depressão do fim da Idade Média - de tal forma contrasta o carater estritamente profissional da luta dos elementos do setor de construção com o cunho idealista e moral das preocupações dos modernos "franco-maçons" mas, de nossa parte, dando como bem delineado o desenvolvimento dos mecanismos psicológicos de resistência às forças de repressão, e, por extensão da opressão, suspeitamos que ela não se limitou a tanto. Mas, sobretudo, estamos convencidos de que há uma conexão clara entre as dificuldades no meio das quais se encerra o período medieval - o que, bem entendido, não passa de uma metáfora, já que a divisão do fluxo da História nada mais é do que um artifício do espírito - e a crise da Maçonaria operativa, e que pesquisas levando mais em conta a significação econômica das atividades da construção, podem contribuir consideravelmente para esclarecer a questão.

VICTOR DEODATO DA SILVA. Bacharel e Licenciado em História pela Universidade de São Paulo. Doutor em História da Civilização Medieval pela Faculdade de Filosofia, Letras e Ciências Humanas da Universidade de São Paulo.

Seguiu cursos de aperfeiçoamento em: Poitiers (Centre d'Études Supérieures de Civilisation Médiévale de l'Université de Poitiers) e Paris (École Nationale des Chartes e École Pratique des Hautes Études, IVe. et Ve Sections), destacando-se a orientação do Prof. Jean GLÉNISSON.

Fortemente revisada, encontra-se no prelo sua tese de doutoramento: A legislação econômica e social consecutiva à Peste Negra de 1348 e sua significaşão no contexto da depressão do fim da Idade Média (Col. "Revista de História") .

Autor de diversos artigos, comunicações e resenhas bibliográficas. 